\section{A) Check for updates}

Cite this: Dalton Trans., 2021, 50 6991

Received 12th April 2021, Accepted 27th April 2021

DOI: $10.1039 / \mathrm{d} 1 \mathrm{dt} 01198 \mathrm{~g}$

rsc.li/dalton

\title{
Novel primary phosphinecarboxamides derived from diamines $\uparrow$
}

\author{
Erica N. Faria, Andrew R. Jupp (DD) and Jose M. Goicoechea (D)*
}

We describe the synthesis of $\mathrm{N}$-functionalised phosphinecarboxamides obtained by reaction of the 2-phosphaethynolate anion $\left(\mathrm{PCO}^{-}\right)$with diamines, specifically hydrazine, methylenediamine and ethylenediamine, in the presence of acid. The resulting neutral compounds can be deprotonated to generate phosphide anions that, when further reacted with electrophiles, form secondary phosphines.

\section{Introduction}

Primary phosphines $\left(\mathrm{H}_{2} \mathrm{PR}\right)$ are interesting chemical feedstocks that have found applications in asymmetric catalysis, ${ }^{1}$ medicinal chemistry, ${ }^{2}$ polymer science, ${ }^{3}$ and the synthesis of extended solids. ${ }^{4}$ However, despite their enormous versatility, the reactivity of this class of compounds remains underexplored compared to primary amines $\left(\mathrm{H}_{2} \mathrm{NR}\right)$. This is largely due to the noxious character, propensity towards oxidation, and the pyrophoric nature of the vast majority of primary phosphines. In recent years, a significant amount of research has been conducted exploring the synthesis and reactivity of airstable primary species in an effort to circumvent many of the pitfalls associated with their manipulation..$^{5-7}$ For example, the use of sterically encumbering substituents has been shown to kinetically stabilise such compounds, allowing for a more thorough exploration of their highly reactive $\mathrm{P}-\mathrm{H}$ bonds. ${ }^{8}$

We recently reported on a unique class of primary phosphines, so-called phosphinecarboxamides or carbamoylphosphines, $\left(\mathrm{RHNC}(\mathrm{O}) \mathrm{PH}_{2}\right)$, that can be accessed by the reaction of the 2-phosphaethynolate anion $\left(\mathrm{PCO}^{-}\right)$with amines in the presence of an acid. ${ }^{9-12}$ This was made possible due to the availability of a phosphorus-containing congener of the cyanate anion, $\mathrm{PCO}^{-}$, which while first reported in $1992,{ }^{13}$ has only come to the fore as a chemical reagent this last decade. ${ }^{14}$ As with other primary phosphines, $\mathrm{H}_{2} \mathrm{NC}(\mathrm{O}) \mathrm{PH}_{2}$ may also be employed as a precursor for metal phosphides, for example in the synthesis of $\mathrm{Zn}_{3} \mathrm{P}_{2}$ thin films. ${ }^{15}$ The main advantage of this family of phosphines is that the carbamoyl group imparts a high degree of stability to such species, making their manipu-

Department of Chemistry, University of Oxford, Chemistry Research Laboratory, 12 Mansfield Road, Oxford, OX1 3TA, UK. E-mail: jose.goicoechea@chem.ox.ac.uk $\dagger$ Electronic supplementary information (ESI) available: Experimental details, analytical data, spectra and computational methods. CCDC 2076831-2076834. For ESI and crystallographic data in CIF or other electronic format see DOI: $10.1039 / \mathrm{d} 1 \mathrm{dt} 01198 \mathrm{~g}$ lation in air straightforward. Further research into the synthesis of phosphinecarboxamides has included mechanochemical methods, ${ }^{16}$ metal-catalysed reactions, ${ }^{17}$ direct reaction of secondary phosphines with cyanates, ${ }^{18}$ and phosphinoboration of isocyanates. ${ }^{19}$ The reactivity of such species has also been demonstrated by coordination to metal centres, ${ }^{20}$ functionalization of $\mathrm{P}-\mathrm{H}$ bonds to afford secondary phosphines, ${ }^{11,21}$ and their use as precursors to generate phosphonates. ${ }^{22}$

These findings prompted us to investigate the accessibility of di-substituted phosphinecarboxamides by employing diamines as starting materials. For this purpose, we studied the reactivity of $\left[\mathrm{Na}(\text { dioxane })_{x}\right][\mathrm{PCO}](x=1.97-2.08)$ towards hydrazine, methylenediamine and ethylenediamine $\left(\mathrm{NH}_{2}\left(\mathrm{CH}_{2}\right)_{n} \mathrm{NH}_{2}\right.$, where $n=0,1,2$, respectively). Herein we report the synthesis of new $N$-functionalised phosphinecarboxamides, their corresponding phosphides (accessed by deprotonation) as well as their secondary phosphine derivatives. ${ }^{23}$

\section{Results and discussion}

\subsection{Synthesis of phosphinecarboxamides}

In the first instance we explored the reactivity of hydrazine hydrochloride, $\mathrm{NH}_{2} \mathrm{NH}_{2} \cdot \mathrm{HCl}$, towards $\left.[\mathrm{Na} \text { (dioxane) })_{x}\right][\mathrm{PCO}]$ in a $1: 1$ ratio (Scheme 1). This reaction gives rise to a product with a triplet resonance at $-139.9 \mathrm{ppm}\left({ }^{1} J_{\mathrm{P}-\mathrm{H}}=206 \mathrm{~Hz}\right)$ in the ${ }^{31} \mathrm{P}$ NMR spectrum, accompanied by a side product observed at $-128.2 \mathrm{ppm}$ as a triplet of doublets $\left({ }^{1} J_{\mathrm{P}-\mathrm{H}}=218 \mathrm{~Hz} ;{ }^{3} \mathrm{~J}_{\mathrm{P}-\mathrm{H}}=5\right.$

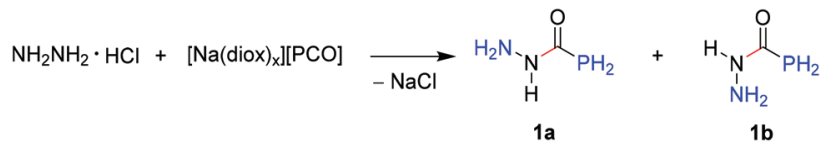

Scheme 1 Reaction of $\mathrm{NH}_{2} \mathrm{NH}_{2} \cdot \mathrm{HCl}$ and $\left.[\mathrm{Na} \text { (dioxane) })_{x}\right][\mathrm{PCO}]$ to afford 1 as its trans (1a) and cis (1b) isomers. 
$\mathrm{Hz}$ ). Both triplets collapse to singlets on proton decoupling, suggesting the formation of the trans- and cis-isomers of $\mathrm{H}_{2} \mathrm{NHNC}(\mathrm{O}) \mathrm{PH}_{2}(\mathbf{1})$.

The peak at $-139.9 \mathrm{ppm}$ can be assigned to the trans isomer of the monosubstituted hydrazine phosphinecarboxamide (or phosphinecarbohydrazide; 1a) and the peak at $-128.2 \mathrm{ppm}$ corresponds to the cis isomer (1b). In the case of the latter species, the $\mathrm{PH}_{2}$ group and the carboxamide proton are in a vicinal trans arrangement to one another relative to the $\mathrm{C}-\mathrm{N}$ bond, allowing for the resolution of the ${ }^{3} \mathrm{~J}_{\mathrm{P}-\mathrm{H}}$ coupling. This data is in agreement with that of the parent species $\left(\mathrm{H}_{2} \mathrm{PC}(\mathrm{O})\right.$ $\mathrm{NH}_{2}$ ), where only the coupling to the trans proton of the amide could be observed. ${ }^{9}$

Accordingly, the ${ }^{1} \mathrm{H}$ NMR spectrum of this mixture reveals two doublets centred at $3.72 \mathrm{ppm}\left({ }^{1} J_{\mathrm{H}-\mathrm{P}}=206 \mathrm{~Hz}\right)$ and $4.02 \mathrm{ppm}\left({ }^{1} J_{\mathrm{H}-\mathrm{P}}=218 \mathrm{~Hz}\right)$ corresponding to the $\mathrm{PH}_{2}$ protons in $\mathbf{1 a}$ and $\mathbf{1 b}$, respectively. These resonances collapse into singlets upon selective phosphorus decoupling. The ${ }^{13} \mathrm{C}\left\{{ }^{1} \mathrm{H}\right\}$ NMR spectrum is also consistent with the proposed structures, with the most diagnostic resonances being in the downfield region of the spectrum, where a doublet at $172.56 \mathrm{ppm}\left({ }^{1} J_{\mathrm{C}-\mathrm{P}}=9 \mathrm{~Hz}\right)$ and a singlet at $181.51 \mathrm{ppm}$ corresponding to the carbonyl carbon in 1a and 1b were observed. The coupling between carbon and phosphorus could not be resolved for $\mathbf{1 b}$, therefore ${ }^{1} \mathrm{H}-{ }^{13} \mathrm{C}$ HMBC $2 \mathrm{D}$ NMR experiments were used to unambiguously assign the peak.

Single crystals of $\mathbf{1 a}$ were obtained from a toluene solution (Fig. 1). X-ray diffraction studies revealed that the proton attached to the $\alpha$-nitrogen is cis to the phosphorus atom relative to the $\mathrm{C}-\mathrm{N}$ bond. The phosphorus presents a pyramidal geometry, while the $\left(\mathrm{NH}_{2}\right) \mathrm{NH}-\mathrm{CO}$ fragment is planar. There are two molecules in the asymmetric unit and, consequently, all the bond metric data are discussed as average values. Bond metric data show a C-P bond length of 1.864(av) $\AA$, which is consistent with a single bond between these atoms, and the $\mathrm{C}-$ $\mathrm{N}$ bond length is 1.334(av) $\AA$, suggesting multiple bond character between carbon and nitrogen. ${ }^{24,25}$

Single crystals of cis-isomer, $\mathbf{1} \mathbf{b}$, could also be obtained by co-crystallisation of the mixture with 18-crown-6, which forms hydrogen bonds with the product (Fig. 2). Bond metric data for this species were similar to those recorded for $\mathbf{1 a}$.

The barrier to rotation around the $\mathrm{C}-\mathrm{N}$ bond was calculated using density functional theory (DFT) at the PBE0/6-31G(d,p) level of theory (Fig. S35†). The transition state was found to be $92 \mathrm{~kJ} \mathrm{~mol}^{-1}$ higher in energy than the more stable isomer. The trans isomer $\mathbf{1 a}$ is more stable than the cis $\mathbf{1 b}$ by $11 \mathrm{~kJ} \mathrm{~mol}^{-1}$. This value is in good agreement with the spectroscopic data obtained, which suggest that $\mathbf{1 a}$ is the major product of the reaction. The relatively high barrier precludes interconversion between isomers due to inherent thermal instability of phosphinecarboxamides.

In an attempt to synthesise a bifunctionalised phosphinecarboxamide derived from hydrazine, i.e. $\mathrm{PH}_{2} \mathrm{C}(\mathrm{O}) \mathrm{NHNHC}(\mathrm{O})$

\$ See ESI $\dagger$ for full experimental details.

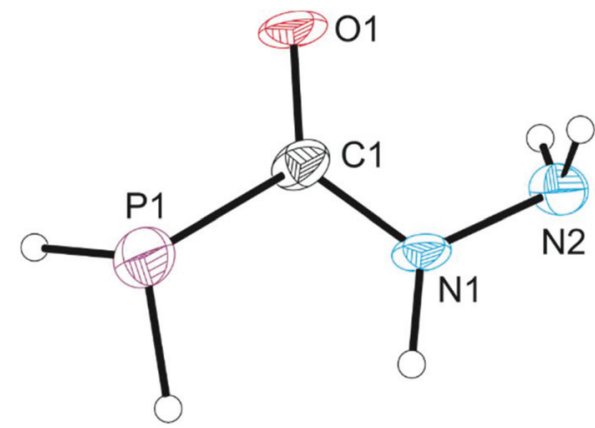

Fig. 1 Molecular structure of the trans isomer of hydrazine monophosphinecarboxamide $1 \mathrm{a}$. Thermal ellipsoids pictured at the $50 \%$ probability level. Selected bond distances (Å) and angles (deg): P1-C1: 1.864(av); C1-O1: 1.224(av); C1-N1: 1.334(av); N1-N2: 1.431(av); O1-C1-P1: 119.2(av); N1-C1-P1: 116.5(av); O1-C1-N1: 124.2(av); C1-N1-N2: 121.4(av).

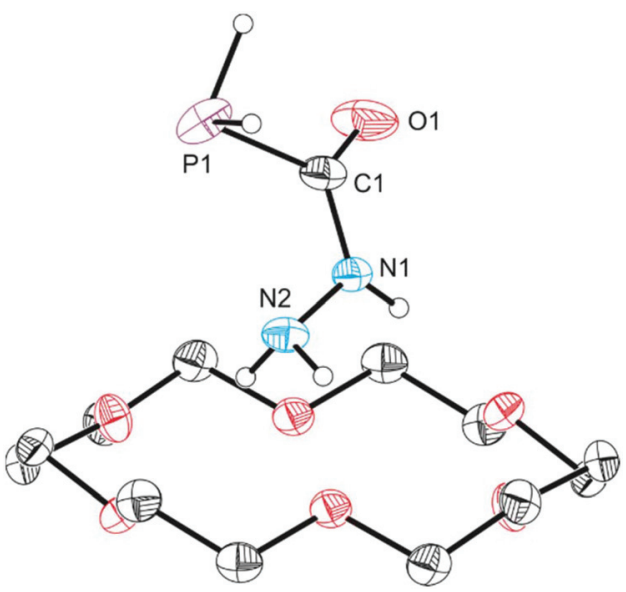

Fig. 2 Molecular structure of the cis isomer of the hydrazine monophosphinecarboxamide in $1 \mathbf{b} \cdot(18-c r o w n-6)_{0.5}$. Thermal ellipsoids pictured at the $50 \%$ probability level. Note that $1 \mathrm{~b}$ crystallises with 0.5 equivalents of 18 -crown- 6 in the asymmetric unit, for clarity, the full 18-crown-6 molecule is pictured. Selected bond distances (Å) and angles (deg): P1-C1: 1.869(av); C1-O1: 1.222(av); C1-N1: 1.339(av); N1N2: 1.407(av); O1-C1-P1: 122.2(av); N1-C1-P1: 114.3(av); O1-C1-N1: 123.4(av); C1-N1-N2: 118.7(av).

$\mathrm{PH}_{2}$, the reaction of $\mathrm{NH}_{2} \mathrm{NH}_{2} \cdot 2 \mathrm{HCl}$ and two equivalents of $\left.[\mathrm{Na} \text { (dioxane })_{x}\right][\mathrm{PCO}]$ was attempted. ${ }^{31} \mathrm{P}\left\{{ }^{1} \mathrm{H}\right\}$ NMR spectroscopy revealed that the product of this reaction was a mixture of $\mathbf{1 a}$ and 1b. Attempts to force the reaction to completion by heating resulted in decomposition. It is likely that the desired compound could not be obtained due to decreased nucleophilicity of the $\beta$-nitrogen in $\mathbf{1 a} / \mathbf{1} \mathbf{b}$ caused by the presence of one phosphinecarboxamide moiety. Consequently, nucleophilic attack of the $\beta$-nitrogen at a second HPCO molecule is slow. HPCO is unstable and short-lived in solution and rapidly decomposes. $^{26}$

We next aimed to extend this research to bridged diamines, by exploring the reactivity of methylenediamine towards $\left.[\mathrm{Na} \text { (dioxane) })_{x}\right][\mathrm{PCO}]$. Interestingly, the product obtained from the reaction of $\mathrm{NH}_{2} \mathrm{CH}_{2} \mathrm{NH}_{2} \cdot 2 \mathrm{HCl}$ and one equivalent of 


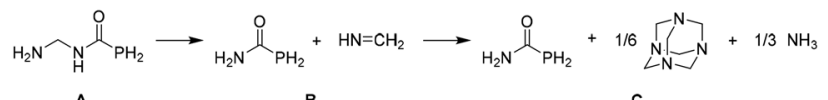

Scheme 2 Proposed decomposition pathway of the methylenediamine mono-phosphinecarboxamide derivative.

$$
\left.\mathrm{H}_{2} \mathrm{~N} \sim \mathrm{NH} \cdot 2 \mathrm{HCl}+2[\mathrm{Na} \text { (diox) })_{x}\right][\mathrm{PCO}] \underset{-2 \mathrm{NaCl}}{\longrightarrow} \prod_{\mathrm{O}} \mathrm{H}_{2} \mathrm{P} \underset{\mathrm{H}}{\mathrm{N}}
$$

Scheme 3 Reaction of $\mathrm{NH}_{2} \mathrm{CH}_{2} \mathrm{CH}_{2} \mathrm{NH}_{2} \cdot 2 \mathrm{HCl}$ and $[\mathrm{Na}$ (dioxane) $]$ [PCO] to afford 2.

$\left.[\mathrm{Na} \text { (dioxane })_{x}\right][\mathrm{PCO}]$ was shown to be the parent phosphinecarboxamide species, $\mathrm{H}_{2} \mathrm{PC}(\mathrm{O}) \mathrm{NH}_{2},{ }^{9}$ and hexamethylenetetramine, also known as urotropine. ${ }^{27}$ We propose that the desired phosphinecarboxamide product is initially formed but methylene imine is quickly eliminated to form the parent species, and that the imine, in turn, oligomerises to yield the urotropine and ammonia (Scheme 2).

The relative energies of the two proposed stages of this decomposition reaction have been calculated (Fig. S36/ Table S11 $\dagger$ ). The final products, $\mathbf{C}$, are $8 \mathrm{~kJ} \mathrm{~mol}^{-1}$ more stable than if the reaction were to stop at the targeted phosphinecarboxamide, $\mathbf{A}$, and $53 \mathrm{~kJ} \mathrm{~mol}^{-1}$ more stable than intermediates B, which explains why urotropine is observed in the ${ }^{1} \mathrm{H}$ NMR spectrum. This pathway is also supported by the presence of a small peak at $0.05 \mathrm{ppm}$ in the ${ }^{1} \mathrm{H}$ NMR spectrum that corresponds to the ammonia formed. ${ }^{28}$

Finally, when $\mathrm{NH}_{2} \mathrm{CH}_{2} \mathrm{CH}_{2} \mathrm{NH}_{2} \cdot 2 \mathrm{HCl}$ and two equivalents of $\left.[\mathrm{Na} \text { (dioxane })_{x}\right][\mathrm{PCO}]$ were reacted, the di-substituted phosphinecarboxamide 2 was obtained (Scheme 3). The ${ }^{31} \mathrm{P}$ NMR spectrum exhibits a triplet at $-132.9 \mathrm{ppm}\left({ }^{1} J_{\mathrm{P}-\mathrm{H}}=208 \mathrm{~Hz}\right)$ that collapses to a singlet on proton decoupling. The ${ }^{1} \mathrm{H}$ NMR spectrum shows a doublet centred at $3.72 \mathrm{ppm}\left({ }^{1} J_{\mathrm{H}-\mathrm{P}}=208 \mathrm{~Hz}\right)$ that also collapses to a singlet upon selective phosphorus decoupling. The ${ }^{13} \mathrm{C}\left\{{ }^{1} \mathrm{H}\right\}$ NMR spectrum shows a doublet at $173.52 \mathrm{ppm}\left({ }^{1} J_{\mathrm{C}-\mathrm{P}}=7 \mathrm{~Hz}\right)$ that corresponds to the carbonyl carbons of the two phosphinecarboxamide moieties coupling to the phosphorus atoms.

Single crystals obtained by slow diffusion of hexane into a pyridine solution of the product confirm the incorporation of two phosphinecarboxamide units to the ethylenediamine (Fig. 3). Bond metric data are consistent with $\mathbf{1 a}$ and $\mathbf{1 b}$.

\subsection{Deprotonation and alkylation studies}

We sought to investigate the relative acidity of the $\mathrm{P}-\mathrm{H}$ bonds in these novel phosphinecarboxamides by exploring their reactivity towards strong non nucleophilic bases such as benzyl potassium (BnK) or potassium bis(trimethylsilyl)amide (KHMDS).

Addition of one equivalent of BnK and 18-crown-6 to 1 in $d_{5}$-pyridine gave rise to a broad doublet at $-109.4 \mathrm{ppm}\left({ }^{1} J_{\mathrm{P}-\mathrm{H}}=\right.$ $150 \mathrm{~Hz})$ and a triplet at $-128.6 \mathrm{ppm}\left({ }^{1} \mathrm{~J}_{\mathrm{P}-\mathrm{H}}=190 \mathrm{~Hz}\right)$ in the ${ }^{31} \mathrm{P}$ NMR spectrum (Fig. 4). In $d_{8}$-THF these resonances were

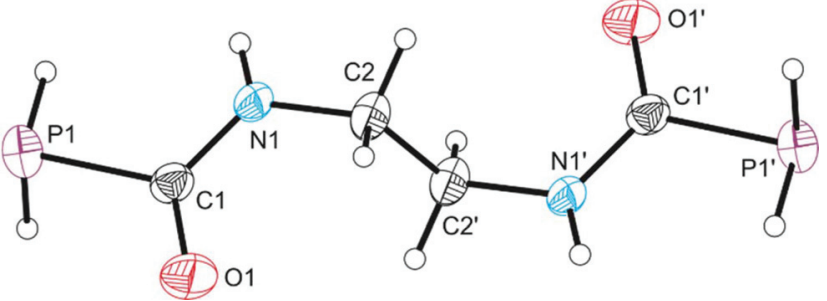

Fig. 3 Molecular structure of 2. Thermal ellipsoids pictured at the $50 \%$ probability level. Symmetry operation ': $-x,-y, 1-z$. Selected bond distances (Å) and angles (deg): P1-C1: 1.8633(12); C1-O1: 1.2275(15); C1-N1: 1.3256(15); N1-C2: 1.4549(15); C2-C2': 1.519(2); O1-C1-P1: 118.38(9); N1-C1-P1: 118.47(8); O1-C1-N1: 123.06(11).

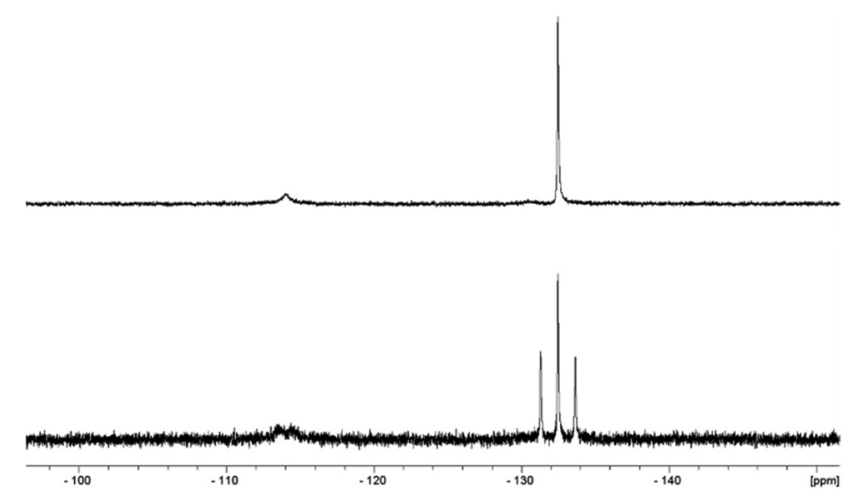

Fig. $4{ }^{31} \mathrm{P}\left\{{ }^{1} \mathrm{H}\right\}$ (top) and ${ }^{31} \mathrm{P}$ (bottom) NMR spectra (in $d_{8}-\mathrm{THF}$ ) of the reaction between 1 and $B n K$ in the presence of 18-crown- 6 .

observed at -114.0 and $-132.5 \mathrm{ppm}$, respectively. These resonances collapse to singlets upon proton decoupling and have an integration ratio of $0.3: 1$, respectively, and they are consistent with deprotonation at the phosphorus and nitrogen sites of the molecule to yield two different anionic species, [K(18crown-6)][3] (Scheme 4).

In the ${ }^{1} \mathrm{H}$ NMR spectrum, two well defined doublets were observed centred at $2.95 \mathrm{ppm}\left({ }^{1} J_{\mathrm{P}-\mathrm{H}}=150 \mathrm{~Hz}\right)$, corresponding to the phosphide product, and another at $4.08 \mathrm{ppm}\left({ }^{1} J_{\mathrm{P}-\mathrm{H}}=\right.$ $190 \mathrm{~Hz}$ ) which corresponds to the amide. These resonances collapse to singlets upon phosphorus decoupling.

Compound 1 possesses three possible deprotonation sites that can yield eight isomers of $\mathbf{3}$ either in their cis or trans forms relative to the $\mathrm{C}-\mathrm{N}$ and $\mathrm{C}-\mathrm{P}$ bonds. The energy of all isomers of 3a-3c (Fig. 5) were calculated using DFT. Calculations revealed that the phosphide trans-cis-3a is the

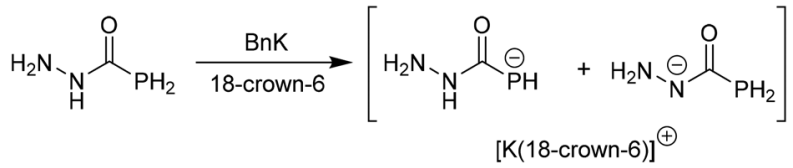

Scheme 4 Reaction of 1, one equivalent of BnK and 18-crown-6 to yield [K(18-crown-6)][3]. 


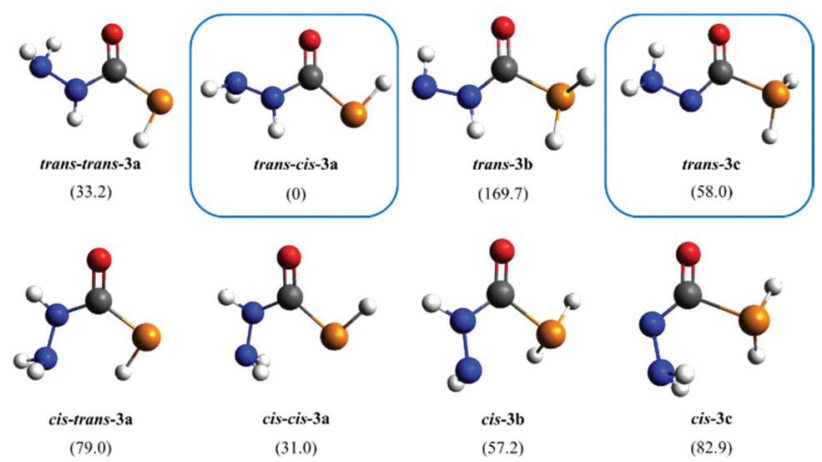

Fig. 5 Possible deprotonation isomers of 3 relative to the $\mathrm{C}-\mathrm{N}$ and $\mathrm{C}-\mathrm{P}$ bonds. The calculated relative $\Delta G$ values are given in brackets in $\mathrm{kJ} \mathrm{mol}{ }^{-1}$. The isomers obtained in solution assigned according to NMR data are highlighted with boxes.

most stable isomer. Based on these results, the broad doublet in the ${ }^{31} \mathrm{P}$ NMR spectrum was assigned as trans-cis-3a, as this is the most stable phosphide isomer, and the triplet has been assigned as trans-3c, resulting from deprotonation of the $\mathrm{NHNH}_{2}$ site, which is $58 \mathrm{~kJ} \mathrm{~mol}^{-1}$ higher in energy (structures highlighted with boxes in Fig. 5).

A variable temperature ${ }^{31} \mathrm{P}$ NMR experiment was performed on a mixture of 1, KHMDS and 18-crown-6 in $d_{8}$-THF over the range of -80 to $+60{ }^{\circ} \mathrm{C}$ (Fig. $\mathrm{S} 16 \dagger$ ). At $-80{ }^{\circ} \mathrm{C}$, it is possible to observe a broad doublet at $-97.0 \mathrm{ppm}\left({ }^{1} J_{\mathrm{P}-\mathrm{H}}=157 \mathrm{~Hz}\right)$, a triplet at $-130.1 \mathrm{ppm}\left({ }^{1} J_{\mathrm{P}-\mathrm{H}}=190 \mathrm{~Hz}\right)$, a triplet of doublets at -132.9 ppm $\left({ }^{1} J_{\mathrm{P}-\mathrm{H}}=217 \mathrm{~Hz},{ }^{3} J_{\mathrm{P}-\mathrm{H}}=8 \mathrm{~Hz}\right)$, and another triplet at $-135.6 \mathrm{ppm}\left({ }^{1} J_{\mathrm{P}-\mathrm{H}}=197 \mathrm{~Hz}\right)$. The broad doublet shifts from $-97.0 \mathrm{ppm}$ to $-\mathbf{1 1 4 . 9} \mathrm{ppm}$ as the temperature increases and two of the triplets disappear over time leaving only one broad triplet at $+60{ }^{\circ} \mathrm{C}$. Interestingly, even though the broad doublet shifted 18 ppm upfield, no coalescence between the doublet and the triplet could be observed as the temperature was increased from $-80^{\circ} \mathrm{C}$ to room temperature. This observation suggests that at room temperature, a slow exchange between these two species might be occurring.

The inability to observe coalescence in this system indicates that if exchange is taking place, it is slow on the NMR timescale. To further investigate this behaviour, a ${ }^{31} \mathrm{P}\left\{{ }^{1} \mathrm{H}\right\}$ 1D EXSY exchange spectroscopy NMR experiment was conducted at room temperature (Fig. S17†) where the phosphide peak was inverted while the signal of the phosphine is monitored as a function of time as the inverted signal relaxes back to equilibrium. As the first peak relaxes, the intensity of the noninverted signal is observed to decrease and, with time, the phosphide resonance regains its initial intensity while the phosphine increases its intensity, which suggests exchange between the two species at room temperature.

Single crystals suitable for X-ray diffraction were obtained from slow diffusion of hexane into a pyridine solution of $[\mathrm{K}$ (18-crown-6)][3]. Interestingly, only [K(18-crown-6)][cis-cis-3a] crystallized from the solution (Fig. 6).

Bond metric data indicate that the $\mathrm{P}-\mathrm{C}, \mathrm{C}-\mathrm{N}$ and $\mathrm{C}-\mathrm{O}$ bond lengths are 1.792(2), 1.383(3) and 1.248(3) ^, respectively.

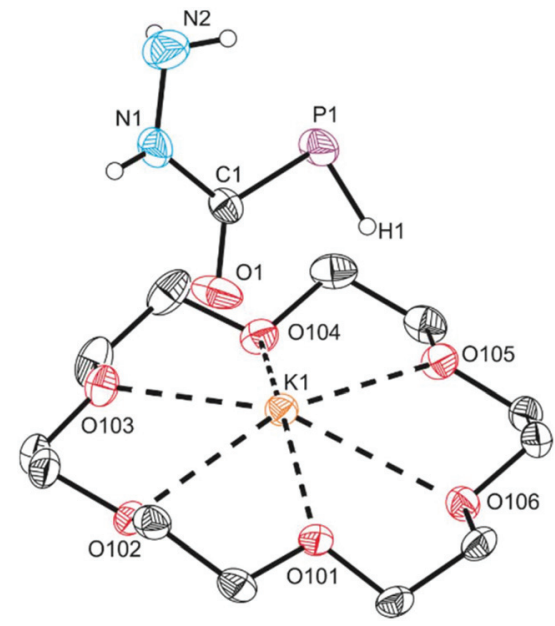

Fig. 6 Molecular structure of [K(18-crown-6)][cis-cis-3a]. Thermal ellipsoids pictured at the $50 \%$ probability level. Selected bond distances (Å) and angles (deg): P1-C1: 1.792(2); C1-O1: 1.248(3); C1-N1: 1.383(3); N1-N2: 1.393(3); O1-K1: 2.679(2); O1-C1-P1: 128.0(2); N1-C1-P1: 115.26(18); O1-C1-N1: 116.7(2); C1-N1-N2: 122.8(2).

Upon deprotonation at the phosphorus, the degree of multiple bond character between phosphorus and carbon increases (1.793(3) vs. 1.869(av) $\AA$ in 1b), while there is a decrease in the multiple bond character between the carbon and nitrogen atoms (1.384(3) vs. 1.339(av) A in 1b). These data are consistent with the bond metrics of previously reported carbamoylphosphides. ${ }^{11}$

Even though cis-cis-3a is $31 \mathrm{~kJ} \mathrm{~mol}^{-1}$ less stable than transcis-3a, the fact that it crystalizes preferentially can be explained by the presence of hydrogen bonds with the neighbouring molecules that favours crystal packing. It should also be mentioned that our gas phase calculations do not take into consideration the presence of the cation or the sequestering agent.

Addition of two equivalents of KHMDS to 2 in pyridine in the presence of two equivalents of 18-crown-6 promotes exclusive deprotonation at the phosphorus atoms, affording compound $\left[\mathrm{K}(18 \text {-crown-6) }]_{2}[\mathbf{4}]\right.$ (Scheme 5$)$.

This selectivity is evident in the ${ }^{31} \mathrm{P}$ NMR spectrum, which exhibits a broad doublet centred at $-98.8 \mathrm{ppm}\left({ }^{1} J_{\mathrm{P}-\mathrm{H}}=150\right.$ $\mathrm{Hz}$ ). With longer reaction times, we observe the presence of a broad triplet at $-256.5 \mathrm{ppm}\left({ }^{1} J_{\mathrm{P}-\mathrm{H}}=134 \mathrm{~Hz}\right)$ that corresponds to $\mathrm{KPH}_{2}$, a decomposition product. These resonances collapse to singlets upon proton decoupling.

The ${ }^{1} \mathrm{H}$ NMR spectrum shows a doublet centred at $2.78 \mathrm{ppm}\left({ }^{1} J_{\mathrm{P}-\mathrm{H}}=150 \mathrm{~Hz}\right)$ that corresponds to the phosphide

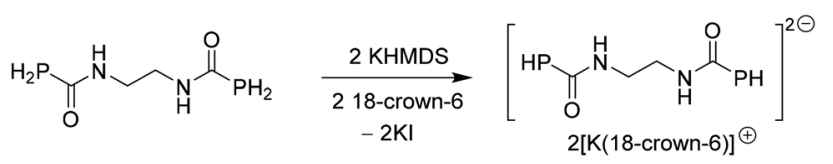

Scheme 5 Reaction of 2, two equivalents of KHMDS and 18-crown-6 to yield $\left[K(18-\text { crown-6) }]_{2}[4]\right.$. 
moiety. The ${ }^{13} \mathrm{C}\left\{{ }^{1} \mathrm{H}\right\}$ NMR spectrum reveals a doublet at $203.79 \mathrm{ppm}\left({ }^{1} J_{\mathrm{C}-\mathrm{P}}=59 \mathrm{~Hz}\right)$. The ${ }^{1} J_{\mathrm{C}-\mathrm{P}}$ coupling constant found for this anion is significantly larger than that of the neutral species $2\left({ }^{1} J_{\mathrm{C}-\mathrm{P}}=7 \mathrm{~Hz}\right)$ presumably due to contraction of the $\mathrm{P}-\mathrm{C}$ bond with an increase of multiple bond character between these two atoms upon deprotonation.

The deprotonated species can be used as precursors to form secondary phosphines. In order to probe this possibility, iodomethane (MeI) was chosen as a simple electrophile to generate $P$-functionalised phosphinecarboxamides.

Iodomethane was added to a [K(18-crown-6)][3] solution to yield the corresponding trans (5a) and cis (5) isomers of the methylated products in solution (Scheme 6).

The ${ }^{31} \mathrm{P}$ NMR spectrum revealed one major doublet of quartets at $-85.4 \mathrm{ppm}\left({ }^{1} J_{\mathrm{P}-\mathrm{H}}=207 \mathrm{~Hz},{ }^{2} J_{\mathrm{P}-\mathrm{H}}=3 \mathrm{~Hz}\right)$ and a minor multiplet at $-86.8 \mathrm{ppm}\left({ }^{1} \mathrm{~J}_{\mathrm{P}-\mathrm{H}}=228 \mathrm{~Hz},{ }^{2} J_{\mathrm{P}-\mathrm{H}}=3 \mathrm{~Hz}\right)$ that are approximately $23 \mathrm{ppm}$ downfield-shifted relative to trans-cis-3a and have been assigned to $\mathbf{5 a}$ and $\mathbf{5 b}$, respectively. These resonances are in a $1: 0.4$ ratio and collapse to singlets upon phosphorus decoupling suggesting that methylation has taken place at the phosphorus centre upon addition of base. Despite [K(18-crown-6)][3] being deprotonated at both nitrogen and phosphorus atoms, there is no evidence of methylation at the nitrogen.

In the ${ }^{1} \mathrm{H}$ NMR spectrum it is possible to observe two clear sets of doublets of quartets centred at $4.04 \mathrm{ppm}\left({ }^{1} J_{\mathrm{P}-\mathrm{H}}=207\right.$ $\left.\mathrm{Hz},{ }^{3} J_{\mathrm{H}-\mathrm{H}}=8 \mathrm{~Hz}\right)$ and $4.60 \mathrm{ppm}\left({ }^{1} J_{\mathrm{P}-\mathrm{H}}=228 \mathrm{~Hz},{ }^{3} J_{\mathrm{H}-\mathrm{H}}=7 \mathrm{~Hz}\right)$. These correspond to $\mathbf{5 a}$ and $\mathbf{5} \mathbf{b}$. As expected, these resonances collapse to quartets upon phosphorus decoupling. The presence of two doublets of doublets at $1.37 \mathrm{ppm}\left({ }^{2} J_{\mathrm{H}-\mathrm{P}}=3 \mathrm{~Hz}\right.$, $\left.{ }^{3} J_{\mathrm{H}-\mathrm{H}}=7 \mathrm{~Hz}\right)$ and $1.36 \mathrm{ppm}\left({ }^{2} J_{\mathrm{H}-\mathrm{P}}=4 \mathrm{~Hz},{ }^{3} J_{\mathrm{H}-\mathrm{H}}=7 \mathrm{~Hz}\right)$ corresponding to the methyl protons was also noted and, with the help of ${ }^{1} \mathrm{H}-{ }^{31} \mathrm{P}$ HMBC experiment, they have been assigned as belonging to $\mathbf{5 a}$ and $\mathbf{5 b}$, respectively. The ${ }^{13} \mathrm{C}\left\{{ }^{1} \mathrm{H}\right\}$ NMR spectrum reveals doublets from the methyl carbons at $1.53 \mathrm{ppm}$ $\left({ }^{1} J_{\mathrm{C}-\mathrm{P}}=9 \mathrm{~Hz}\right)$ and $1.83 \mathrm{ppm}\left({ }^{1} J_{\mathrm{C}-\mathrm{P}}=6 \mathrm{~Hz}\right)$ that, with the help of ${ }^{1} \mathrm{H}-{ }^{13} \mathrm{C}$ HMBC, have been attributed to $\mathbf{5 a}$ and $\mathbf{5 b}$, respectively. The carbonyl carbons of $\mathbf{5 a}$ and $\mathbf{5 b}$ could also be observed as doublets at $177.68 \mathrm{ppm}\left({ }^{1} J_{\mathrm{C}-\mathrm{P}}=13 \mathrm{~Hz}\right)$ and $185.08 \mathrm{ppm}\left({ }^{1} J_{\mathrm{C}-\mathrm{P}}=\right.$ $6 \mathrm{~Hz}$ ).

The ${ }^{31} \mathrm{P}$ NMR spectrum also displays $1 \%$ of the product of double methylation of the phosphorus atom which is apparent as a broad peak at $-44.2 \mathrm{ppm}$. This happens when there is an excess of KHMDS and MeI in solution. Excess base promotes a second deprotonation at the phosphorus that is then attacked by a second equivalent of electrophile.

Two equivalents of KHMDS were added to a mixture of MeI and 2 to yield the corresponding methylated product (6). The

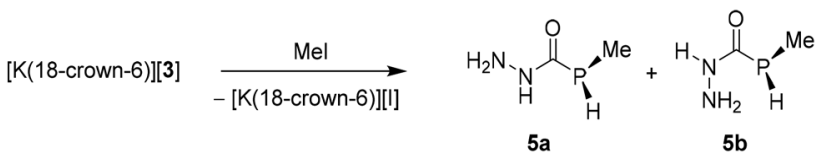

Scheme 6 Reaction of [K(18-crown-6)][3] and Mel to yield 5a and $5 \mathbf{b}$.
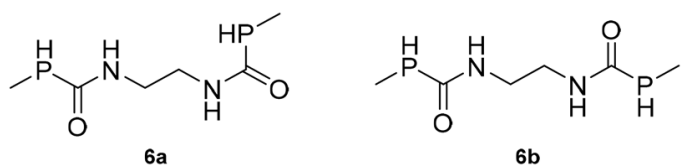

Fig. 7 Trans-cis (6a) and trans-trans (6b) isomers of 6.

${ }^{31} \mathrm{P}$ NMR spectrum exhibits three overlapping doublet of quartets, two of equal integration centred at -81.08 and $-81.11 \mathrm{ppm}\left({ }^{1} J_{\mathrm{P}-\mathrm{H}}=207 \mathrm{~Hz},{ }^{3} J_{\mathrm{H}-\mathrm{H}}=3 \mathrm{~Hz}\right)$, and a smaller one at $-81.08 \mathrm{ppm}\left({ }^{1} J_{\mathrm{P}-\mathrm{H}}=207 \mathrm{~Hz},{ }^{3} J_{\mathrm{H}-\mathrm{H}}=3 \mathrm{~Hz}\right)$ that is only apparent in the ${ }^{31} \mathrm{P}\left\{{ }^{1} \mathrm{H}\right\}$ NMR spectrum. These resonances collapse to singlets upon proton decoupling and are $51.5 \mathrm{ppm}$ downfield-shifted relative to 2 and $17.6 \mathrm{ppm}$ downfield-shifted relative to 4. We propose that the two main overlapping resonances observed correspond to the trans-cis isomers of the product of single methylation at the phosphorus atoms (6a) and that the minor product is the trans-trans isomer (6b) (Fig. 7).

Other than the desired products obtained, it is also possible to observe the presence of two overlapping septets at -41.0 and $-41.1 \mathrm{ppm}$ accompanied by a triplet at $-132.7 \mathrm{ppm}$ in the ${ }^{31} \mathrm{P}$ NMR spectrum. These resonances are complementary and correspond to the product of double methylation of one of the phosphorus atoms in a molecule while leaving the other phosphorus untouched.

In the ${ }^{1} \mathrm{H}$ NMR spectrum, the doublets originating from the $\mathrm{PH}_{2}$ moiety in 2 are replaced by two overlapping doublets of quartets centred at $4.02 \mathrm{ppm}\left({ }^{1} J_{\mathrm{H}-\mathrm{P}}=207 \mathrm{~Hz},{ }^{3} J_{\mathrm{H}-\mathrm{H}}=3 \mathrm{~Hz}\right.$; and ${ }^{1} J_{\mathrm{H}-\mathrm{P}}=207 \mathrm{~Hz},{ }^{3} J_{\mathrm{H}-\mathrm{H}}=3 \mathrm{~Hz}$ ) that correspond to the $\mathrm{P}-\mathrm{H}$ protons in the trans-cis isomer (6a). These resonances also overlap with the methylene units from each isomer, but they become very clear in the ${ }^{1} \mathrm{H}\left\{{ }^{31} \mathrm{P}\right\}$ NMR spectrum, where they collapse to quartets upon phosphorus decoupling. The presence of a doublet of doublets at $1.34 \mathrm{ppm}\left({ }^{2} J_{\mathrm{H}-\mathrm{P}}=3 \mathrm{~Hz},{ }^{3} J_{\mathrm{H}-\mathrm{H}}=\right.$ $7 \mathrm{~Hz}$ ) corresponding to the methyl protons was also noted. The ${ }^{13} \mathrm{C}\left\{{ }^{1} \mathrm{H}\right\}$ NMR spectrum reveals doublets from the methyl carbons at $1.74 \mathrm{ppm}\left({ }^{1} J_{\mathrm{C}-\mathrm{P}}=8 \mathrm{~Hz}\right)$ and these appear to have the same chemical shift for the two isomers (6a). The carbonyl carbons of 6 a were also observed as two overlapping doublets at 178.82 and $178.80 \mathrm{ppm}\left({ }^{1} J_{\mathrm{C}-\mathrm{P}}=11 \mathrm{~Hz}\right)$.

\section{Conclusions}

We have shown that the synthesis and characterization of two novel phosphinecarboxamides and their subsequent functionalization is possible by reacting diamines with sodium phosphaethynolate salts. It has been shown that, in general, despite having two possible deprotonation sites, the phosphorus-bound protons are more acidic than the amide protons and that phosphinecarboxamides are not able to tolerate basic media. The phosphides obtained can be further reacted with simple electrophiles rendering $P$-functionalised phosphinecarboxamides. The generation of molecules featur- 
ing multiple phosphinecarboxamide moieties, such as 2, highlights the potential of this method for the synthesis of bespoke chelating ligands from abundant poly(amine) precursors.

\section{Conflicts of interest}

There are no conflicts to declare.

\section{Acknowledgements}

We thank the Conselho Nacional de Desenvolvimento Científico e Tecnológico ( $\mathrm{CNPq}$ ) of the Brazilian government (studentship ENF; Process number 233778/2014-4) and the EPSRC (DTA studentship ARJ) for funding.

\section{Notes and references}

1 (a) X. Li, K. D. Robinson and P. P. Gaspar, J. Org. Chem., 1996, 61, 7702-7710; (b) A. Marinetti and J.-P. Genêt, C. R. Chim., 2003, 6, 507-514; (c) T. Clark and C. Landis, Tetrahedron: Asymmetry, 2004, 15, 2123-2137; (d) G. Hoge and B. Samas, Tetrahedron: Asymmetry, 2004, 15, 21552157; (e) D. J. Brauer, K. W. Kottsieper, S. Roßenbach and O. Stelzer, Eur. J. Inorg. Chem., 2003, 2003, 17481755.

2 K. V. Katti, H. Gali, C. J. Smith and D. E. Berning, Acc. Chem. Res., 1998, 32, 9-17.

3 (a) T. N. Hooper, M. A. Huertos, T. Jurca, S. D. Pike, A. S. Weller and I. Manners, Inorg. Chem., 2014, 53, 3716-3729; (b) H. Dorn, R. A. Singh, J. A. Massey, A. J. Lough and I. Manners, Angew. Chem., Int. Ed., 1999, 38, 3321-3323.

4 J. T. Scheper, K. C. Jayaratne, L. M. Liable-Sands, G. P. A. Yap, A. L. Rheingold and C. H. Winter, Inorg. Chem., 1999, 38, 4354-4360.

5 M. Brynda, Coord. Chem. Rev., 2005, 249, 20132034.

6 B. Stewart, A. Harriman and L. J. Higham, Organometallics, 2011, 30, 5338-5343.

7 J. T. Fleming and L. J. Higham, Coord. Chem. Rev., 2015, 297-298, 127-145.

8 Selected examples of the use of sterically encumbered substituents to stabilize primary phosphines: (a) M. Yoshifuji, K. Shibayama and N. Inamoto, J. Am. Chem. Soc., 1983, 105, 2495-2497; (b) K. Tsuji, S. Sasaki and M. Yoshifuji, Heteroat. Chem., 1998, 9, 607-613; (c) B. Twamley, C.-S. Hwang, N. J. Hardman and P. Power, J. Organomet. Chem., 2000, 609, 152-160; (d) For more examples, see ref. 5 and the references therein.

9 A. R. Jupp and J. M. Goicoechea, J. Am. Chem. Soc., 2013, 135, 19131-19134.

10 T. P. Robinson and J. M. Goicoechea, Chem. - Eur. J., 2015, 21, 5727-5731.
11 A. R. Jupp, G. Trott, É. Payen De La Garanderie, J. D. G. Holl, D. Carmichael and J. M. Goicoechea, Chem. Eur. J., 2015, 21, 8015-8018.

12 E. N. Faria, A. R. Jupp and J. M. Goicoechea, Chem. Commun., 2017, 53, 7092-7095.

13 G. Becker, W. Schwarz, N. Seidler and M. Westerhausen, Z. Anorg. Allg. Chem., 1992, 612, 72-82.

14 For a recent review of the chemistry of the 2-phosphaethynolate ion see: J. M. Goicoechea and H. Grützmacher, Angew. Chem., Int. Ed., 2018, 57, 16968-16994.

15 S. V. F. Beddoe, S. D. Cosham, A. N. Kulak, A. R. Jupp, J. M. Goicoechea and G. Hyett, Dalton Trans., 2018, 47, 9221-9225.

16 (a) Y.-H. Wu, Z.-F. Li, W.-P. Wang, X.-C. Wang and Z.-J. Quan, Eur. J. Org. Chem., 2017, 5546-5553; (b) Z.-F. Li, W.-P. Wang, X.-C. Wang and Z.-J. Quan, Chin. J. Org. Chem., 2020, 40, 1563-1570.

17 (a) H. R. Sharpe, A. M. Geer, W. Lewis, A. J. Blake and D. L. Kays, Angew. Chem., Int. Ed., 2017, 56, 4845-4848; (b) A. C. Behrle and J. A. R. Schmidt, Organometallics, 2013, 32, 1141-1149.

18 (a) G. P. Papp and S. A. Buckler, J. Org. Chem., 1966, 31, 588-589; (b) L. G. Vaughan and R. V. Lindsey Jr., J. Org. Chem., 1968, 33, 3088-3089; (c) M. Itazaki, T. Matsutani, T. Nochida, T. Moriuchi and H. Nakazawa, Chem. Commun., 2020, 56, 443-445.

19 S. J. Geier, J. H. W. LaFortune, D. Zhu, S. C. Kosnik, C. L. B. Macdonald, D. W. Stephan and S. A. Westcott, Dalton Trans., 2017, 46, 10876-10885.

20 (a) M. B. Geeson, A. R. Jupp, J. E. McGrady and J. M. Goicoechea, Chem. Commun., 2014, 50, 12281-12284; (b) M. Navrátil, E. N. Faria, G. Panahy, I. Císařová, J. M. Goicoechea and P. Štěpnička, Dalton Trans., 2020, 49, 8645-8651.

21 X.-G. Chen, Q.-L. Wu, F. Hou, X.-C. Wang and Z.-J. Quan, Synlett, 2019, 73-76.

22 (a) Y.-H. Wu, Q.-L. Wu, W.-P. Wang, X.-C. Wang and Z.-J. Quan, Adv. Synth. Catal., 2018, 360, 2382-2388; (b) F. Hou, X.-P. Du, A. I. Alduma, Z.-F. Li, C.-D. Huo, X.-C. Wang, X.-F. Wu and Z.-J. Quan, Adv. Synth. Catal., 2020, 362, 4755-4760.

23 For review articles on phosphinecarboxamides and related species see: (a) O. Kühl, Coord. Chem. Rev., 2006, 250, 2867-2915; (b) P. Štěpnička, Chem. Soc. Rev., 2012, 41, 4273-4305.

24 P. Pyykkö and M. Atsumi, Chem. - Eur. J., 2009, 15, 186197.

25 P. Pyykkö and M. Atsumi, Chem. - Eur. J., 2009, 15, 1277012779.

26 R. Hinz, C. Labbow, C. Rennick, A. Schulz and J. M. Goicoechea, Angew. Chem., Int. Ed., 2017, 56, 39113915.

27 K. Eller, E. Henkes, R. Rossbacher and H. Höke, "Amines, Aliphatic" in Ullmann's Encyclopedia of Industrial Chemistry, Wiley-VCH Verlag GmbH, 2020.

28 F. Haase and J. Sauer, J. Phys. Chem., 1994, 98, 3083. 